\title{
COPD in primary care: a time of opportunity
}

Chronic obstructive pulmonary disease (COPD) has come to the fore at last in this new millenium in the thinking of health services and clinicians. But its late recognition is badly timed as the world struggles with the aftermath of a recession that will challenge all healthcare spending. In the UK the government's Consultation on a Strategy for Services for Chronic Obstructive Pulmonary Disease (COPD) in England' has recently been completed after a prolonged gestation of 5 years. The consultation document is 177 pages and makes 24 recommendations. Since its publication, the political guard has changed at the UK Department of Health and a new government has to decide how to proceed in a time of austerity. Will there be new funding to address the recommendations in the COPD strategy document? The recommendations come with 35 actions, most of which will require the investment of funding and will be subject to its availability.

COPD has come out of a prolonged spell in the healthcare doldrums. Nihilism about its treatment was matched by an undeserved disinterest in sufferers by their clinical attendants, many of whom saw the condition as a self-inflicted dirty disease. This disregard by current doctors and nurses whose predecessors had been the social leaders of the smoking addiction is sadly ironic. The new dawn for COPD has come on the back of significant developments in its treatment. Prominent among these has been pulmonary rehabilitation - a programme of exercise, education, and social interaction - which has exceeded the benefits of the new drugs in terms of its impact on quality of life. ${ }^{2}$ But the momentum behind the growing prominence given to COPD in the thinking of healthcare policy chiefs and clinicians has come mainly from the proof of the clinical effectiveness of its drug treatments.

Clinical trials of tiotropium, long-acting beta-agonists salmeterol and formoterol, and the combination inhaled long-acting beta-agonists and corticosteroids, have shown beyond doubt the value of these drugs in symptom control, but particularly in the prevention of acute exacerbations and hospital admissions. ${ }^{3-5}$ These effects have been sustained over 3 to 4 years in the most recent trials. It seems inevitable that the combined inhaled long-acting beta-agonists and corticosteroids will also be shown to reduce mortality.

These advances in the care of COPD are reflected internationally in the Global initiative for chronic Obstructive Lung Disease guidelines. ${ }^{6}$ In the UK they have led to the adoption of incentive payments through the Quality and Outcomes Framework (QOF) to GPs who maintain COPD disease registers and who record spirometry and dyspnoea severity in their COPD patients.

The impact of the preventative effect of the drugs in reducing the risk of exacerbations and hospital admissions is limited by the incompleteness of GPs' disease registers. The majority of people with COPD are treated predominantly in general practice. It is clear from the annual QOF reporting of COPD prevalence on the lists of GPs that the identification by GPs of people with COPD in the UK has remained static in the 10 years since Soriano and colleagues first published their findings on the prevalence of diagnosed COPD. ${ }^{8,9}$ We now know more about the distribution of COPD prevalence and the role of socioeconomic deprivation from the paper by Simpson and colleagues in this edition of the BJGP. ${ }^{10}$

Socioeconomic deprivation is a key determinant of the prevalence of COPD and its severity. Simpson and colleagues have shown that the prevalence of COPD was twice as high among people living in socioeconomically deprived areas as it was among those living in affluent areas. ${ }^{10}$ The low rate of smoking cessation among those in socioeconomically deprived areas emphasises the inequality that exists in COPD and its treatment. Added to these differences is the geographic variation in prevalence and smoking cessation most evident between the north-east of England and the south-east. The prevalence of COPD is rising worldwide. Simpson and colleagues may be premature in announcing a peak in prevalence in the UK, but with COPD currently the second cause of death in China and due to become the fourth most common cause worldwide, lessons we learn about its management in the UK may have wide application.

The most important intervention at any stage of COPD care is smoking cessation which should be a generic healthcare approach applied to the whole population irrespective of disease state. In patients who undergo spirometry, Parkes et al in 2008 have shown that information about lung age can significantly improve smoking cessation rates. ${ }^{11}$

Many of the initiatives detailed in the UK COPD strategy document need to be undertaken if the impact of COPD is to be reduced beyond what can be achieved by smoking cessation. Among the highest priorities should be pulmonary rehabilitation which offers the best option for improvement in quality of life. A second priority is the improved detection and registration of COPD which would enable better secondary prevention through drug prescribing. Both have significant cost implications. In 2006 the Healthcare Commission in the UK (now the Care Quality Commission) reported that only 5\% of patients with COPD had received pulmonary rehabilitation. This was despite the assertion by the UK National Institute for Health and Clinical Excellence that all patients with COPD who are impaired by the disease should have access to pulmonary rehabilitation. Primary care trusts (locality health care commissioners in the UK) are commissioning more pulmonary rehabilitation, but it remains restricted largely to hospitals in most areas. 
Improving the detection of COPD is costly. Not only do GPs have to identify those with COPD not currently on their lists, but when COPD is suspected, spirometry is essential to confirm the diagnosis. Spirometry is highly variable in general practice and is likely to remain so until funding is available to provide training and promote quality assurance in primary care. ${ }^{12}$ Broekhuizen and colleagues, in this issue of the BJGP, screened patients consulting GPs for persistent cough using spirometry, and found COPD in almost $30 \% .^{13}$ Their approach may need to be broadened to the presentation of all respiratory symptoms in people over 40 years. If not we will fail in the UK to bridge the gap between the current prevalence of diagnosed COPD of $1.65 \%$ and the estimated prevalence of the disease which is greater than $3 \%$. In a recent study in Holland the rate of diagnosed prevalence of COPD has been shown to be $5.4 \%$, a figure that is more reflective of the global prevalence of the disease. ${ }^{14}$

The challenge of COPD has never been felt at a better time in terms of the options for meeting it. The opportunity to scale up the primary and secondary prevention of the disease should not be missed. The potential rewards are huge. In the UK COPD is the cause of death of almost as many people as lung cancer and it is the second most common cause of emergency admission. We should not allow the recession turn our faces against these patients who have been so neglected.

\section{Patrick White,}

Senior Lecturer, Department of Primary Care and Public Health Sciences, King's College London.

\section{Provenance}

Commissioned; not peer reviewed.

\section{REFERENCES}

1. Department of Health. Consultation on a Strategy for Services for Chronic Obstructive Pulmonary Disease (COPD) in England. London: Department of Health, 2010.

2. Lacasse $Y$, Goldstein R, Lasserson TJ, Martin S. Pulmonary rehabilitation for chronic obstructive pulmonary disease. Cochrane Database Syst Rev 2006; (4): CD003793.

3. Wedzicha JA, Calverley PM, Seemungal TA, et al. The prevention of chronic obstructive pulmonary disease exacerbations by salmeterol/fluticasone propionate or tiotropium bromide. Am J Respir Crit Care Med 2008; 177(1): 19-26.

4. Calverley PM, Anderson JA, Celli B, et al. Salmeterol and fluticasone propionate and survival in chronic obstructive pulmonary disease. N Engl J Med 2007; 356(8): 775-789.

5. Tashkin DP, Celli B, Senn S, et al. A 4-year trial of tiotropium in chronic obstructive pulmonary disease. N Engl J Med 2008; 359(15): 1543-1554.

6. Global Initiative for Chronic Obstructive Lung Disease. Global strategy for the diagnosis, management, and prevention of chronic obstructive pulmonary disease (updated 2009).

http://www.goldcopd.com/Guidelineitem.asp?l1=2\&l 2=1\&intId=2003 (accessed 15 Jun 2010).

7. Roland M. Linking physicians' pay to the quality of care - a major experiment in the United Kingdom. N Engl J Med 2004; 351(14): 1448-1454.

8. Information Centre for Health and Social Care. Quality and Outcomes Framework 2008/9. http://www.ic.nhs.uk/statistics-and-datacollections/audits-and-performance/the-quality-andoutcomes-framework/the-quality-and-outcomesframework-2008-09. (accessed 15 Jun 2010).

9. Soriano JB, Maier WC, Egger P, et al. Recent trends in physician diagnosed COPD in women and men in the UK. Thorax 2000; 55(9): 789-794.

10. Simpson CR, Hippisley-Cox J, Sheikh A. Trends in the epidemiology of chronic obstructive pulmonary disease in England: a national study of 51804

patients. Br J Gen Pract 2010; DOI:

10.3399/bjgp10X514729.

11. Parkes G, Greenhalgh T, Griffin M, Dent R. Effect on smoking quit rate of telling patients their lung age: the Step2quit randomised controlled trial. BMJ 2008 336(7644): 598-600.

12. Levy ML, Quanjer PH, Booker R, et al. Diagnostic spirometry in primary care: Proposed standards for general practice compliant with American Thoracic Society and European Respiratory Society recommendations: a General Practice Airways Group (GPIAG) document, in association with the

Association for Respiratory Technology \& Physiology (ARTP) and Education for Health. Prim Care Respir 2009; 18(3): 130-47.

13. Broekhuizen BDL, Sachs APE, Hoes AW, et al. Undetected chronic obstructive pulmonary disease and asthma in people older than 50 presenting with persistent cough in primary care. Br J Gen Pract 2010; 60: 489-494.

14. Bischoff EWMA, Schermer TRJ, Bor H, et al. Trends in COPD prevalence and exacerbation rates in Dutch primary care. Br J Gen Pract 2009; 59(569): 927-933.

DOI: 10.3399/bjgp10X514693

\section{ADDRESS FOR CORRESPONDENCE}

\section{Patrick White}

King's College London, Department of Primary Care and Public Health Sciences, 9th Floor, Capital House,

42 Weston Street, London SE1 3QD.

E-mail: patrick.white@kcl.ac.uk 